\title{
Characterizing Hospitalizations for Pediatric Concussion and Trends in Care
}

\author{
Tara Rhine, MD, MS ${ }^{1,2 \star}$, Terri Byczkowski, PhD ${ }^{1,2}$, Mekibib Altaye, PhD ${ }^{1,3}$, Shari L. Wade, PhD ${ }^{1,4}$, Lynn Babcock, MD, MS 1,2
}

'Department of Pediatrics, University of Cincinnati College of Medicine, Cincinnati, Ohio; ${ }^{2}$ Division of Emergency Medicine, Cincinnati Children's Hospital Medical Center, Cincinnati, Ohio; ${ }^{3}$ Division of Biostatistics and Epidemiology, Cincinnati Children's Hospital Medical Center, Cincinnati, Ohio; ${ }^{4}$ Division of Physical Medicine and Rehabilitation, Cincinnati Children's Hospital Medical Center, Cincinnati, Ohio.

BACKGROUND: Children hospitalized for concussion may be at a higher risk for persistent symptoms, but little is known about this subset of children.

OBJECTIVE: Delineate a cohort of children admitted for concussion, describe care practices received, examine factors associated with prolonged length of stay (LOS) or emergency department (ED) readmission, and investigate changes in care over time.

DESIGN/SETTING: Retrospective analysis of data submitted by 40 pediatric hospitals to the Pediatric Health Information System.

PATIENTS: Children 0 to 17 years old admitted with a primary diagnosis of concussion from 2007 to 2014.

MEASUREMENTS: Descriptive statistics characterized this cohort and care practices delivered, logistic regression identified factors associated with a LOS of $\geq 2$ days and ED readmission, and trend analyses assessed changes in care over time.
RESULTS: Of the 10,729 children admitted for concussion, $68.7 \%$ received intravenous pain or antiemetic medications. Female sex, adolescent age, and having government insurance were all associated $(P \leq .02)$ with increased odds of LOS $\geq 2$ days and ED revisit. Proportions of children receiving intravenous ondansetron (slope $=$ $1.56, P=.001$ ) and ketorolac (slope $=0.61$, $P<.001)$ increased over time, and use of neuroimaging (slope $=-1.75, P<.001)$ decreased.

CONCLUSIONS: Although concussions are usually self-limited, hospitalized children often receive intravenous therapies despite an unclear benefit. Factors associated with prolonged LOS and ED revisit were similar to predictors of postconcussive syndrome. Since there has been an increased use of specific therapeutics, prospective evaluation of their relationship with concussion recovery could lay the groundwork for evidencedbased admission criteria and optimize recovery. Journal of Hospital Medicine 2018;13:673-680. Published online first April 25, 2018. (C) 2018 Society of Hospital Medicine

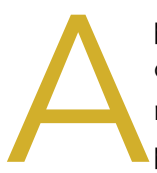

pproximately $14 \%$ of children who sustain a concussion are admitted to the hospital, ${ }^{1}$ although admission rates reportedly vary substantially among pediatric hospitals. ${ }^{2}$ Children hospitalized for concussion may be at a higher risk for persistent postconcussive symptoms, ${ }^{3,4}$ yet little is known about this subset of children and how they are managed while in the hospital. Characterizing children hospitalized for concussion and describing the inpatient care they received will promote hypothesis generation for further inquiry into indications for admission, as well as the relationship between inpatient management and concussion recovery.

We described a cohort of children admitted to 40 pediatric hospitals primarily for concussion and detailed care delivered during hospitalization. We explored individual-level factors and their association with prolonged length of stay (LOS) and emergency department (ED) readmission. Finally, we evaluat-

*Address for correspondence: Tara Rhine, MD, MS, Cincinnati Children's Hospital Medical Center, 3333 Burnet Avenue, ML 2008, Cincinnati, OH, 45229; Phone: 513-280-3551; Fax: 513-636-7967, E-mail: tara.rhine@cchmc.org

Received: October 27, 2017; Revised: January 23, 2018; Accepted: February 10,2018

๑) 2018 Society of Hospital Medicine DOI 10.12788/jhm.2968 ed if there had been changes in inpatient care over the eightyear study period.

\section{PATIENTS AND METHODS \\ Study Design}

The Institutional Review Board determined that this retrospective cohort study was exempt from review.

\section{Data Source}

The Children's Hospital Association's Pediatric Health Information System (PHIS) is an administrative database from pediatric hospitals located within 17 major metropolitan areas in the United States. Data include: service dates, patient demographics, payer type, diagnosis codes, resource utilization information (eg, medications), and hospital characteristics. ${ }^{1,5}$ De-identified data undergo reliability and validity checks prior to inclusion. ${ }^{1,5}$ We analyzed data from 40 of 43 hospitals that contributed inpatient data during our study period. Two hospitals were excluded due to inconsistent data submission, and one removed their data.

\section{Study Population}

Data were extracted for children 0 to 17 years old who were admitted to an inpatient or observational unit between January 1, 2007 and December 31, 2014 for traumatic brain injury 
(TBI). Children were identified using International Classification of Diseases, Clinical Modification, Ninth Revision (ICD-9-CM) diagnosis codes that denote TBI per the Centers for Disease Control (CDC): 800.0-801.9, 803.0-804.9, 850-854.1, and 959.01.6-8 To examine inpatient care for concussion, we only retained children with a primary (ie, first) concussion-related diagnosis code (850.0-850.99) for analyses. For patients with multiple visits during our study period, only the index admission was analyzed. We refined our cohort using two injury scores calculated from ICD-9-CM diagnosis codes using validated ICDMAP-90 injury coding software., ${ }^{6,10-12}$ The Abbreviated Injury Scale (AIS) ranges from one (minor injury) to six (not survivable). The total Injury Severity Score (ISS) is based on six body regions (head/neck, face, chest, abdomen, extremity, and external) and calculated by summing the squares of the threeworst AIS scores. ${ }^{13} \mathrm{~A}$ concussion receives a head AIS score of two if there is an associated loss of consciousness or a score of 1 if there is not; therefore, children were excluded if the head AIS score was $>2$. We also excluded children with the following features, as they may be indicative of more severe injuries that were likely the cause of admission: ISS > 6, secondary diagnosis code of skull fracture or intracranial injury, intensive care unit (ICU) or operating room (OR) charges, or a LOS $>7$ days. Because some children are hospitalized for potentially abusive minor head trauma pending a safe discharge plan, we excluded children 0 to 4 years of age with child abuse, which was determined using a specific set of diagnosis codes (E960-E96820, 995.54, and 995.55) similar to previous research. ${ }^{14}$

\section{Data Elements and Outcomes Outcomes}

Based on previous reports, ${ }^{1,15}$ a LOS $\geq 2$ days distinguished a typical hospitalization from a prolonged one. ED revisit was identified when a child had a visit with a TBI-related primary diagnosis code at a PHIS hospital within 30 days of initial admission and was discharged home. We limited analyses to children discharged, as children readmitted may have had an initially missed intracranial injury.

\section{Patient Characteristics}

We examined the following patient variables: age, race, sex, presence of chronic medical condition, payer type, household income, area of residence (eg, rural versus urban), and mechanism of injury. Age was categorized to represent early childhood (0 to 4 years), school age (5 to 12 years), and adolescence (12 to 17 years). Race was grouped as white, black, or other (Asian, Pacific Islander, American Indian, and "other" per PHIS). Ethnicity was described as Hispanic/Latino or not Hispanic/Latino. Children with medical conditions lasting at least 12 months and comorbidities that may impact TBI recovery were identified using a subgrouping of ICD-9-CM codes for children with "complex chronic conditions". ${ }^{16}$ Payer type was categorized as government, private, and self-pay. We extracted a PHIS variable representing the 2010 median household income for the child's home zip code and categorized it into quartiles based on the Federal Poverty Level for a family of $4 .{ }^{17,18}$ Area of residence was defined using a Rural-Urban Commuting Area (RUCA) classification system ${ }^{19}$ and grouped into large urban core, suburban area, large rural town, or small rural town/isolated rural area. ${ }^{17}$ Mechanism of injury was determined using E-codes and categorized using the CDC injury framework, ${ }^{20}$ with sports-related injuries identified using a previously described set of E-codes. ${ }^{1}$ Mechanisms of injury included fall, motor vehicle collision, other motorized transport (eg, all-terrain vehicles), sports-related, struck by or against (ie, objects), and all others (eg, cyclists).

\section{Hospital Characteristics}

Hospitals were characterized by region (Northeast, Central, South, and West) and size (small <200, medium 200-400, and large $>400$ beds). The trauma-level accreditation was identified with Level 1 reflecting the highest possible trauma resources.

\section{Medical Care Variables}

Care variables included medications, neuroimaging, and cost of stay. Medication classes included oral non-narcotic analgesics [acetaminophen, ibuprofen, and others (aspirin, tramadol, and naproxen)], oral narcotics (codeine, oxycodone, and narcotic-non-narcotic combinations), intravenous (IV) non-narcotics (ketorolac), IV narcotics (morphine, fentanyl, and hydromorphone), antiemetics (ondansetron, metoclopramide, and phenothiazines (prochlorperazine, chlorpromazine, and promethazine)], maintenance IV fluids (dextrose with electrolytes or $0.45 \%$ sodium chloride), and resuscitation IV fluids ( $0.9 \%$ sodium chloride or lactated Ringer's solution). Receipt of neuroimaging was determined if head computed tomography (CT) had been conducted at the admitting hospital. Adjusted cost of stay was calculated using a hospital-specific cost-to-charge ratio with additional adjustments using the Center for Medicare \& Medicaid's Wage Index.

\section{Statistical Analyses}

Descriptive statistics were calculated for individual, injury, and hospital, and care data elements, LOS, and ED readmissions. The number of children admitted with TBI was used as the denominator to assess the proportion of pediatric TBI admissions that were due to concussions. To identify factors associated with prolonged LOS (ie, $\geq 2$ days) and ED readmission, we employed a mixed models approach that accounted for clustering of observations within hospitals. Independent variables included age, sex, race, ethnicity, payer type, household income, RUCA code, chronic medical condition, and injury mechanism. Models were adjusted for hospital location, size, and trauma-level accreditation. The binary distribution was specified along with a logit link function. A two-phase process determined factors associated with each outcome. First, bivariable models were developed, followed by multivariable models that included independent variables with $P$ values $<$ .25 in the bivariable analysis. Backward step-wise elimination was performed, deleting variables with the highest $P$ value one at a time. After each deletion, the percentage change in odds ratios was examined; if variable removal resulted in $>10 \%$ 
TABLE 1. Characteristics of Concussion Admissions to 40 PHIS Hospitals from 2007-2014 (N = 10,729)

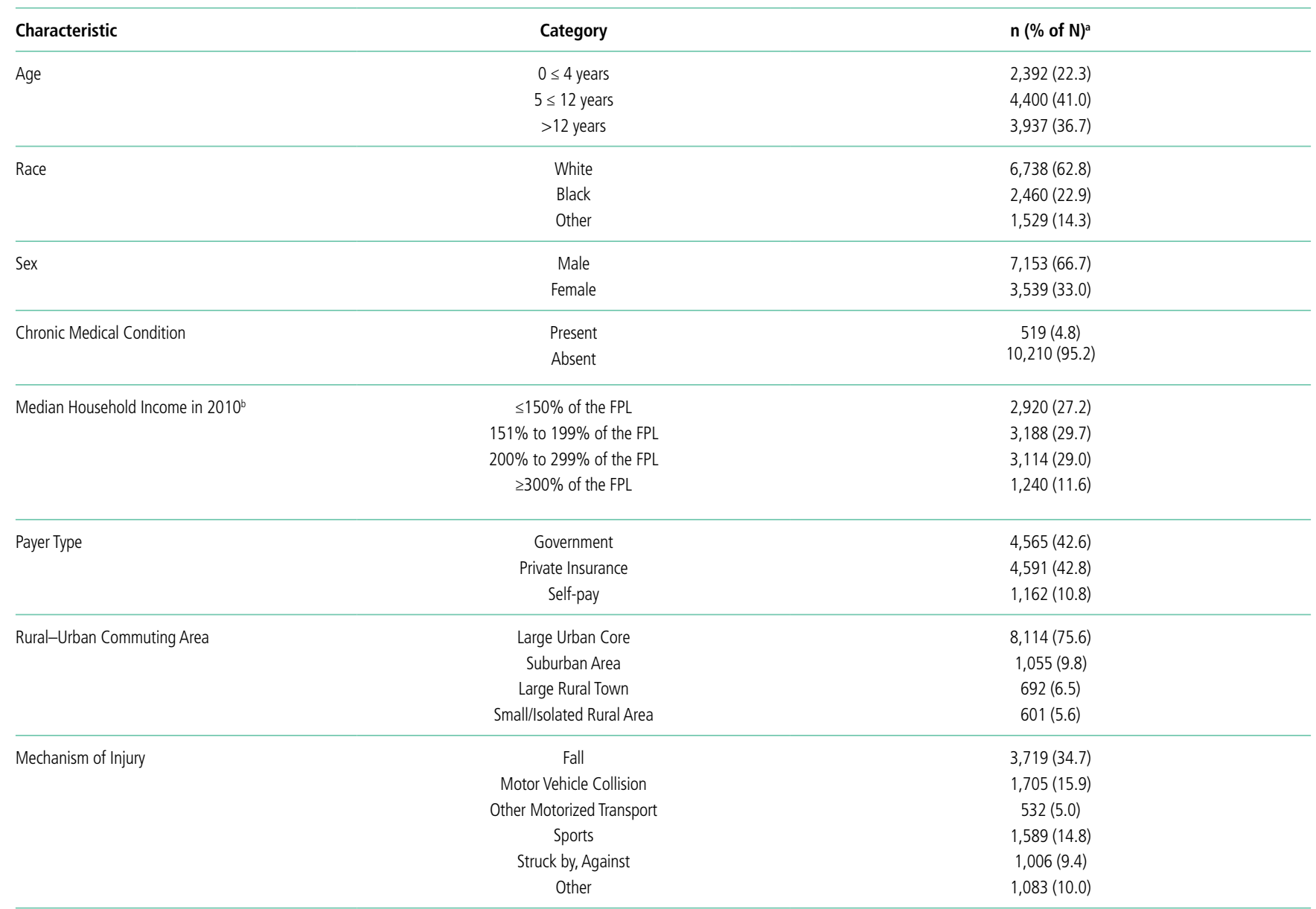

aData were missing for the following variables: Race $(n=2)$, Income $(n=267)$, Payer type $(n=411)$, Rural-Urban $(n=267)$, Mechanism of injury $(n=1,095)$

${ }^{b}$ As previously described, this variable was categorized into quartiles based on the Federal Poverty Level for a family of 4 per the US Department of Health and Human Services: $\leq 150 \%$ of the FPL $(\leq \$ 33,525), 151 \%$ to $199 \%$ of the FPL $(\$ 33,526-\$ 44,700), 200 \%$ to $299 \%$ of the FPL $(\$ 44,701-\$ 67,050)$, and $\geq 300 \%$ of the FPL $(\geq \$ 67,051)$

Abbreviations: FPL, Federal Poverty Line; PHIS, Pediatric Health Information System.

change, the variable was retained as a potential confounder. This process was repeated until all remaining variables were significant $(P<.05)$ with the exception of potential confounders. Finally, we examined the proportion of children receiving selected care practices annually. Descriptive and trend analyses were used to analyze adjusted median cost of stay. Analyses were performed using SAS software (Version 9.3, SAS Institute Inc., Cary, North Carolina).

\section{RESULTS}

Over 8 years, 88,526 children were admitted to 40 PHIS hospitals with a TBI-related diagnosis, among whom 13,708 had a primary diagnosis of concussion. We excluded 2,973 children with 1 or more of the following characteristics: a secondary diagnosis of intracranial injury $(n=58)$, head AIS score $>2(n=$ $218)$, LOS $>7$ days $(n=50)$, OR charges $(n=132)$, ICU charges $(n=1947)$, and ISS $>6(n=568)$. Six additional children aging 0 to 4 years were excluded due to child abuse. The remaining 10,729 children, averaging 1,300 hospitalizations annually, were identified as being hospitalized primarily for concussion.
Table 1 summarizes the individual characteristics for this cohort. The average (standard deviation) age was 9.5 (5.1) years. Ethnicity was missing for $25.3 \%$ and therefore excluded from the multivariable models. Almost all children had a head AIS score of two (99.2\%), and the majority had a total ISS $\leq 4$ (73.4\%). The majority of admissions were admitted to Level 1 trauma-accredited hospitals (78.7\%) and medium-sized hospitals (63.9\%).

The most commonly delivered medication classes were non-narcotic oral analgesics (53.7\%), dextrose-containing IV fluids (45.0\%), and antiemetic medications (34.1\%). IV and oral narcotic use occurred in $19.7 \%$ and $10.2 \%$ of the children, respectively. Among our cohort, 16.7\% received none of these medication classes. Of the 8,940 receiving medication, $32.6 \%$ received a single medication class, $29.5 \%$ received two classes, $20.5 \%$ three classes, $11.9 \%$ four classes, and $5.5 \%$ received five or more medication classes. Approximately 15\% $(n=$ 1,597 ) received only oral medications, among whom $91.2 \%$ ( $n$ $=1,457)$ received only non-narcotic analgesics and $3.9 \%(n=$ 63) received only oral narcotic analgesics. The majority (69.5\%) 
TABLE 2. Characteristics Associated with an Inpatient Length of Stay of Two or More Days in Children Admitted for Concussion

\begin{tabular}{|c|c|c|c|c|}
\hline \multirow[t]{2}{*}{ Characteristic } & \multicolumn{2}{|c|}{ Bivariable Analysis $^{a}$} & \multicolumn{2}{|c|}{ Multivariable Analysis ${ }^{a}$} \\
\hline & Odds Ratio (95\% CL) & $P$ Value & Odds Ratio (95\% CL) & $P$ Value \\
\hline Age & & $<.0001$ & & $<.001$ \\
\hline$>12$ years & $1.45(1.25,1.69)$ & & $1.41(1.21,1.65)$ & \\
\hline $0 \leq 4$ years & $1.05(0.87,1.26)$ & & $1.09(0.89,1.32)$ & \\
\hline $5 \leq 12$ years & REFERENCE & & REFERENCE & \\
\hline Sex & & $<.0001$ & & $<.0001$ \\
\hline Female & $1.5(1.30,1.72)$ & & $1.53(1.33,1.77)$ & \\
\hline Male & REFERENCE & & REFERENCE & \\
\hline Race & & .04 & & - \\
\hline Black & $1.17(0.98,1.39)$ & & - & \\
\hline Other & $1.26(1.03,1.54)$ & & - & \\
\hline White & REFERENCE & & - & \\
\hline Payer Type & & $<.01$ & & $<.01$ \\
\hline Self-pay & $1.24(0.99,1.56)$ & & $1.17(0.93,1.47)$ & \\
\hline Government & $1.27(1.10,1.48)$ & & $1.30(1.12,1.51)$ & \\
\hline Private Insurance & REFERENCE & & REFERENCE & \\
\hline Median Household Income in 2010 & & .08 & & - \\
\hline$<150 \%$ of the FPL & $1.38(1.07,1.79)$ & & - & \\
\hline $151 \%$ to $199 \%$ of the FPL & $1.36(1.04,1.73)$ & & - & \\
\hline $200 \%$ to $299 \%$ of the FPL & $1.23(0.96,1.59)$ & & - & \\
\hline$\geq 300 \%$ of the FPL & REFERENCE & & - & \\
\hline Rural-Urban Commuting Area & & .50 & & - \\
\hline Suburban Area & $1.08(0.86,1.36)$ & & - & \\
\hline Large rural town & $1.22(0.92,1.61)$ & & - & \\
\hline Small/isolated rural area & $1.11(0.82,1.50)$ & & - & \\
\hline Large urban core & REFERENCE & & - & \\
\hline Chronic Medical Condition & & $<.0001$ & & $<.0001$ \\
\hline Present & $2.12(1.65,2.72)$ & & $2.22(1.73,2.86)$ & \\
\hline Absent & REFERENCE & & REFERENCE & \\
\hline Mechanism of Injury & & $<.0001$ & & $<.0001$ \\
\hline Fall & $0.80(0.65,0.97)$ & & $0.78(0.62,0.98)$ & \\
\hline Motor vehicle collision & $1.38(1.11,1.72)$ & & $1.29(1.03,1.62)$ & \\
\hline Other motorized transport & $1.14(0.83,1.55)$ & & $1.10(0.80,1.52)$ & \\
\hline Struck by, against & $0.90(0.69,1.17)$ & & $0.87(0.66,1.14)$ & \\
\hline Other & $1.10(0.86,1.41)$ & & $1.12(0.87,1.45)$ & \\
\hline Sports & REFERENCE & & REFERENCE & \\
\hline
\end{tabular}

${ }^{a}$ All models included covariates that were adjusted for the hospital's size based on the number of inpatient beds, trauma-level accreditation, and geographic region of the county. The multivariable model was constructed including all independent variables with $P$ values $<.25$ in the bivariable analysis. Backward step-wise elimination was performed by deleting variables with the highest $P$ value one at a time, and if the removal of a variable resulted in a greater than $10 \%$ change in odds ratios, it was left in the model as a potential confounder.

Abbreviation: FPL, Federal Poverty Line.

received a head $\mathrm{CT}$.

The median (interquartile range) LOS was one (1) day with $11.3 \%$ ( $n=1,209$ ) of the children being hospitalized $\geq 2$ days. ED revisits with a primary TBI-related diagnoses were infrequent at $3.8 \%(n=411)$. As summarized in Table 2, children with protracted LOS were more likely to be female, $>12$ years of age, and publicly insured. Children injured in a motor vehicle collision (relative to sports-related injuries) and with chronic medical conditions were also more likely to have prolonged LOS. Children $>12$ years old, female, and publicly insured were significantly more likely to incur ED revisits (Table 3 ).

Table 4 summarizes medication administration trends over time. Oral non-narcotic administration increased significantly (slope $=0.99, P<.01$ ) with the most pronounced change occurring in ibuprofen use (slope $=1.11, P<.001)$. Use of the IV non-narcotic ketorolac (slope $=0.61, P<.001$ ) also increased significantly, as did the proportion of children receiving antiemetics (slope $=1.59, P=.001$ ), with a substantial increase in ondansetron use (slope $=1.56, P=.001$ ). The proportion of children receiving head CTs decreased linearly over time 
TABLE 3. Characteristics Associated with Emergency Department Revisits within 30 Days of Inpatient Admission for Concussion

\begin{tabular}{|c|c|c|c|c|}
\hline \multirow[t]{2}{*}{ Characteristic } & \multicolumn{2}{|c|}{ Bivariable Analysis $^{a}$} & \multicolumn{2}{|c|}{ Multivariable Analysis $^{\mathrm{a}}$} \\
\hline & $\begin{array}{c}\text { Odds Ratio } \\
\text { (95\% CL) }\end{array}$ & $P$ Value & $\begin{array}{c}\text { Odds Ratio } \\
\text { (95\% CL) }\end{array}$ & $P$ Value \\
\hline Age & & .01 & & .01 \\
\hline$>12$ years & $1.46(1.12,1.89)$ & & $1.49(1.15,1.93)$ & \\
\hline $0 \leq 4$ years & $1.38(1.03,1.86)$ & & $1.27(0.94,1.93)$ & \\
\hline $5 \leq 12$ years & REFERENCE & & REFERENCE & \\
\hline Sex & & .01 & & $<.01$ \\
\hline Female & $1.34(1.07,1.69)$ & & $1.37(1.09,1.73)$ & \\
\hline Male & REFERENCE & & REFERENCE & \\
\hline Race & & $<.01$ & & - \\
\hline Black & $1.45(1.11,1.89)$ & & - & \\
\hline Other & $0.81(0.55,1.19)$ & & - & \\
\hline White & REFERENCE & & - & \\
\hline Payer Type & & $<.01$ & & .02 \\
\hline Self-pay & $0.87(0.56,1.36)$ & & $0.84(0.53,1.31)$ & \\
\hline Government & $1.45(1.14,1.83)$ & & $1.35(1.1,1.75)$ & \\
\hline Private insurance & REFERENCE & & REFERENCE & \\
\hline Median Household Income in 2010 & & .08 & & .04 \\
\hline$<150 \%$ of the FPL & $1.37(0.92,2.05)$ & & $1.42(0.93,2.18)$ & \\
\hline $151 \%$ to $199 \%$ of the FPL & $1.05(0.70,1.57)$ & & $1.05(0.69,1.59)$ & \\
\hline $200 \%$ to $299 \%$ of the FPL & $0.97(0.64,1.45)$ & & $0.92(0.61,1.39)$ & \\
\hline$\geq 300 \%$ of the FPL & REFERENCE & & REFERENCE & \\
\hline Rural-Urban Commuting Area & & $<.01$ & & $<.001$ \\
\hline Suburban area & $0.91(0.62,1.31)$ & & $0.98(0.64,1.44)$ & \\
\hline Large rural town & $0.5(0.28,0.9)$ & & $0.46(0.26,0.83)$ & \\
\hline Small/isolated rural area & $0.2(0.08,0.5)$ & & $0.18(0.07,0.44)$ & \\
\hline Large Urban Core & REFERENCE & & REFERENCE & \\
\hline Chronic Medical Condition & & .61 & & - \\
\hline Present & $0.87(0.50,1.50)$ & & - & \\
\hline Absent & REFERENCE & & - & \\
\hline Mechanism of Injury & & .08 & & - \\
\hline Fall & $1.11(0.79,1.55)$ & & - & \\
\hline Motor vehicle collision & $1.43(0.99,2.07)$ & & - & \\
\hline Other motorized transport & $0.76(0.41,1.41)$ & & - & \\
\hline Struck by, against & $1.27(0.83,1.94)$ & & - & \\
\hline Other & $0.82(0.51,1.32)$ & & - & \\
\hline Sports & REFERENCE & & - & \\
\hline
\end{tabular}

aAll models included covariates that were adjusted for the hospital's size based on the number of inpatient beds, trauma-level accreditation, and geographic region of the county. The multivariable model was constructed including all independent variables with $P$ values $<.25$ in the bivariable analysis. Backward step-wise elimination was performed by deleting variables with the highest $P$ value one at a time, and if the removal of a variable resulted in a greater than $10 \%$ change in odds ratios, it was left in the model as a potential confounder.

Abbreviation: FPL, Federal Poverty Line.

(slope $=-1.75, P<.001$ ), from $76.1 \%$ in 2007 to $63.7 \%$ in 2014 . Median cost, adjusted for inflation, increased during our study period $(P<.001$ ) by approximately $\$ 353$ each year, reaching $\$ 11,249$ by 2014 .

\section{DISCUSSION}

From 2007 to 2014, approximately 15\% of children admitted to PHIS hospitals for TBI were admitted primarily for concussion. Since almost all children had a head AIS score of two and an ISS $\leq 4$, our data suggest that most children had an associated loss of consciousness and that concussion was the only injury sustained, respectively. This study identified important subgroups that necessitated inpatient care but are rarely the focus of concussion research (eg, toddlers and those injured due to a motor vehicle collision). Most children (83.3\%) received medications to treat common postconcussive symptoms (eg, pain and nausea), with almost half receiving three or more medication classes. Factors associated with the development of postconcussive syndrome (eg, female sex and adolescent age $)^{4,21}$ were significantly associated with hospitalization of two 
TABLE 4. Trends in Medication Administration to Children Admitted for Concussion from 2007-2014 (N=10,729)

\begin{tabular}{|c|c|c|c|c|c|c|c|c|c|c|}
\hline Medication Classes & $\begin{array}{c}2007 \\
(n=1,192)\end{array}$ & $\begin{array}{c}2008 \\
(n=1,237)\end{array}$ & $\begin{array}{c}2009 \\
(n=1,288)\end{array}$ & $\begin{array}{c}2010 \\
(n=1,343)\end{array}$ & $\begin{array}{c}2011 \\
(n=1,337)\end{array}$ & $\begin{array}{c}2012 \\
(n=1,494)\end{array}$ & $\begin{array}{c}2013 \\
(n=1,517)\end{array}$ & $\begin{array}{c}2014 \\
(n=1,321)\end{array}$ & Slope $(\boldsymbol{\beta})$ & $P$ Value \\
\hline Oral Non-narcotic Analgesics ${ }^{\mathrm{a}}$ & 50.4 & 50.9 & 52.8 & 53.0 & 55.2 & 51.5 & 56.7 & 58.4 & 0.99 & $<.01^{b}$ \\
\hline Acetaminophen & 41.5 & 42.9 & 45.3 & 44.5 & 43.7 & 40.2 & 47.1 & 47.3 & 0.54 & .18 \\
\hline Ibuprofen & 16.4 & 16.4 & 17.9 & 19.3 & 21.4 & 21.0 & 22.1 & 24.0 & 1.11 & $<.001^{\mathrm{b}}$ \\
\hline Oral Narcotics ${ }^{\mathrm{a}}$ & 8.7 & 9.4 & 10.0 & 10.4 & 8.8 & 11.4 & 10.7 & 11.4 & 0.33 & $.03^{b}$ \\
\hline Codeine & 0.4 & 0.1 & 0.2 & 0.1 & 0.0 & 0.1 & 0.0 & 0.0 & -0.04 & $.03^{\mathrm{b}}$ \\
\hline Oxycodone & 1.1 & 1.2 & 1.5 & 1.7 & 1.9 & 2.0 & 2.3 & 3.6 & 0.29 & $.001^{\mathrm{b}}$ \\
\hline Combination & 7.3 & 8.1 & 8.6 & 8.9 & 6.9 & 9.4 & 8.6 & 8.0 & 0.09 & .53 \\
\hline \multicolumn{11}{|l|}{ IV Non-narcotic Analgesic } \\
\hline Hydromorphone & 0.3 & 0.7 & 0.3 & 0.3 & 0.2 & 0.3 & 0.6 & 0.1 & -0.03 & .38 \\
\hline Antiemetics $^{\mathrm{a}}$ & 25.9 & 31.0 & 31.4 & 34.1 & 35.1 & 37.4 & 38.3 & 37.1 & 1.59 & $.001^{\mathrm{b}}$ \\
\hline Ondansetron & 25.2 & 30.2 & 30.9 & 33.4 & 34.6 & 36.8 & 37.2 & 36.1 & 1.56 & $.001^{\mathrm{b}}$ \\
\hline Metoclopramide & 1.5 & 1.6 & 0.9 & 0.7 & 0.4 & 1.3 & 1.0 & 1.1 & -0.05 & .45 \\
\hline Phenothiazines & 0.5 & 0.3 & 1.3 & 0.7 & 0.5 & 0.7 & 1.1 & 0.9 & 0.06 & .32 \\
\hline IV resuscitation fluids & 23.2 & 22.1 & 19.6 & 22.3 & 24.8 & 22.3 & 22.5 & 21.4 & -0.01 & .98 \\
\hline IV maintenance fluids & 53.0 & 46.5 & 43.6 & 43.6 & 42.3 & 42.2 & 44.3 & 46.0 & -0.77 & .17 \\
\hline \multicolumn{11}{|c|}{$\begin{array}{l}\text { aRepresents the total percentage of children who received that category of medication; in cases where a child received two or more medications of the same category, the child was counted } \\
\text { only once toward the medication category's total number }\end{array}$} \\
\hline
\end{tabular}

or more days and ED revisit within 30 days of admission. In the absence of evidenced-based guidelines for inpatient concussion management, we identified significant trends in care, including increased use of specific pain [ie, oral and IV nonsteroidal anti-inflammatory drugs (NSAIDs)] and antiemetic (ie, ondansetron) medications and decreased use of head CT. Given the number of children admitted and receiving treatment for concussion symptomatology, influences on the decision to deliver specific care practices, as well as the impact and benefit of hospitalization, require closer examination.

Our study extends previous reports from the PHIS database by characterizing children admitted for concussion. ${ }^{1}$ We found that children admitted for concussion had similar characteristics to the broader population of children who sustain concussion (eg, school-aged children, male, and injured due to a fall or during sports). ${ }^{1,3,22}$ However, approximately $20 \%$ of the cohort were less than five years old, and less is known regarding appropriate treatment and outcomes of concussion in this age group..$^{23}$ Uncertainty regarding optimal management and a young child's inability to articulate symptoms may contribute to a physician's decision to admit for close observation. Similar to Blinman et al., we found that a substantial proportion of children admitted with concussion were injured due to a motor ve- hicle collision, ${ }^{3}$ suggesting that although sports-related injuries are responsible for a significant proportion of pediatric concussions, children injured by other preventable mechanisms may also be incurring significant concussive injuries. Finally, the majority of our cohort was from an urban core, relative to a rural area, which is likely a reflection of the regionalization of trauma care, as well as variations in access to health care.

Although most children recover fully from concussion without specific interventions, 20\%-30\% may remain symptomatic at 1 month, 3,4,21,24 and children who are hospitalized with concussion may be at higher risk for protracted symptoms. While specific individual or injury-related factors (eg, female sex, adolescent age, and injury due to motor vehicle collision) may contribute to more significant postconcussive symptoms, it is unclear how inpatient management affects recovery trajectory. Frequent sleep disruptions associated with inpatient care ${ }^{25}$ contradict current acute concussion management recommendations for physical and cognitive rest ${ }^{26}$ and could potentially impair symptom recovery. Additionally, we found widespread use of NSAIDs, although there is evidence suggesting that NSAIDs may potentially worsen concussive symptoms. ${ }^{26}$ We identified an increase in medication usage over time despite limited evidence of their effectiveness for pediatric concus- 
sion. ${ }^{27-29}$ This change may reflect improved symptom screening $^{4,30}$ and/or increased awareness of specific medication safety profiles in pediatric trauma patients, especially for NSAIDs and ondansetron. Although we saw an increase in NSAID use, we did not see a proportional decrease in narcotic use. Similarly, while two-thirds of our cohort received IV medications, there is controversy about the need for IV fluids and medications for other pediatric illnesses, with research demonstrating that IV treatment may not reduce recovery time and may contribute to prolonged hospitalization and phlebitis. ${ }^{31,32}$ Thus, there is a need to understand the therapeutic effectiveness and benefits of medications and fluids on postconcussion recovery.

Neuroimaging rates for children receiving ED evaluation for concussion have been reported to be up to $60 \%-70 \%,{ }^{1,22}$ although a more recent study spanning 2006 to 2011 found a 35\%$40 \%$ head CT rate in pediatric patients by hospital-based EDs in the United States. ${ }^{33}$ Our results appear to support decreasing head CT use over time in pediatric hospitals. Hospitalization for observation is costly ${ }^{1}$ but could decrease a child's risk of malignancy from radiation exposure. Further work on balancing cost, risk, and shared decision-making with parents could guide decisions regarding emergent neuroimaging versus admission.

This study has limitations inherent to the use of an administrative dataset, including lack of information regarding why the child was admitted. Since the focus was to describe inpatient care of children with concussion, those discharged home from the ED were not included in this dataset. Consequently, we could not contrast the ED care of those discharged home with those who were admitted or assess trends in admission rates for concussion. Although the overall number of concussion admissions has continued to remain stable over time, ${ }^{1}$ due to a lack of prospectively collected clinical information, we are unable to determine whether observed trends in care are secondary to changes in practice or changes in concussion severity. However, there has been no research to date supporting the latter. Ethnicity was excluded due to high levels of missing data. Cost of stay was not extensively analyzed given hospital variation in designation of observational or inpatient status, which subsequently affects billing. ${ }^{34}$ Rates of neuroimaging and ED revisit may have been underestimated since children could have received care at a non-PHIS hospital. Similarly, the decrease in the proportion of children receiving neuroimaging over time may have been associated with an increase in children being transferred from a non-PHIS hospital for admission, although with increased regionalization in trauma care, we would not expect transfers of children with only concussion to have significantly increased. Finally, data were limited to the pediatric tertiary care centers participating in PHIS, thereby reducing generalizability and introducing selection bias by only including children who were able to access care at PHIS hospitals. Although the care practices we evaluated (eg, NSAIDs and head (T) are available at all hospitals, our analyses only reflect care delivered within the PHIS.

Concussion accounted for $15 \%$ of all pediatric TBI admissions during our study period. Further investigation of potential factors associated with admission and protracted recovery (eg, adolescent females needing treatment for severe symptomatology) could facilitate better understanding of how hospitalization affects recovery. Additionally, research on acute pharmacotherapies (eg, IV therapies and/or inpatient treatment until symptoms resolve) is needed to fully elucidate the acute and long-term benefits of interventions delivered to children.

\section{Acknowledgments}

The authors would like to thank Colleen Mangeot, biostatistician with extensive PHIS knowledge, who contributed to database creation and statistical analysis and Yanhong (Amy) Liu, research database programmer, who developed the database, ran quality assurance measures, and cleaned all study data.

Disclosures: The authors have nothing to disclose.

Funding: This study was supported by grant R40 MC 268060102 from the Maternal and Child Health Research Program, Maternal and Child Health Bureau (Title V, Social Security Act), Health Resources and Services Administration, Department of Health and Human Services. The funding source was not involved in development of the study design; in the collection, analysis and interpretation of data; or in the writing of this report.

\section{References}

1. Colvin JD, Thurm C, Pate BM, Newland JG, Hall M, Meehan WP. Diagnosis and acute management of patients with concussion at children's hospitals. Arch Dis Child. 2013;98(12):934-938.

2. Bourgeois FT, Monuteaux MC, Stack AM, Neuman MI. Variation in emergency department admission rates in US children's hospitals. Pediatrics. 2014;134(3):539-545.

3. Blinman TA, Houseknecht E, Snyder C, Wiebe DJ, Nance ML. Postconcussive symptoms in hospitalized pediatric patients after mild traumatic brain injury. J Pediatr Surg. 2009;44(6):1223-1228.

4. Babcock L, Byczkowski T, Wade SL, Ho M, Mookerjee S, Bazarian JJ. Predicting postconcussion syndrome after mild traumatic brain injury in children and adolescents who present to the emergency department. JAMA pediatrics. 2013;167(2):156-161.

5. Conway $\mathrm{PH}$, Keren R. Factors associated with variability in outcomes for children hospitalized with urinary tract infection. The Journal of pediatrics. 2009;154(6):789-796

6. Services UDoHaH. International classification of diseases, 9th Revision, Clinical modification (ICD-9CM). Washington, DC: US Department of Health and Human Services. Public Health Service, Health Care Financing Administration 1989

7. Marr AL, Coronado VG. Annual data submission standards. Central nervous system injury surveillance. In: US Department of Health and Human Services PHS, CDC, ed. Atlanta, GA 2001

8. Organization WH. International classification of diseases: manual on the international statistical classification of diseases, injuries, and cause of death. In: Organization WH, ed. 9th rev. ed. Geneva, Switerland 1977.

9. Centers for Disease Control and Prevention, National Center for Injury Prevention and Control. Report to Congress on mild traumatic brain injury in the United States: steps to prevent a serious public health problem. Atlanta, GA: Centers for Disease Control and Prevention; 2003.

10. Mackenzie E, Sacco WJ. ICDMAP-90 software: user's guide. Baltimore, Maryland: Johns Hopkins University and Tri-Analytics. 1997:1-25.

11. MacKenzie EJ, Steinwachs DM, Shankar B. Classifying trauma severity based on hospital discharge diagnoses. Validation of an ICD-9CM to AIS-85 conversion table. Med Care. 1989;27(4):412-422.

12. Fleischman RJ, Mann NC, Dai M, et al. Validating the use of ICD-9 code mapping to generate injury severity scores. J Trauma Nurs. 2017;24(1):4-14.

13. Baker SP, O'Neill B, Haddon W, Jr., Long WB. The injury severity score: a method for describing patients with multiple injuries and evaluating emergency care. The Journal of trauma. 1974;14(3):187-196.

14. Wood JN, Feudtner C, Medina SP, Luan X, Localio R, Rubin DM. Variation in occult injury screening for children with suspected abuse in selected US children's hospitals. Pediatrics. 2012;130(5):853-860.

15. Yang J, Phillips G, Xiang H, Allareddy V, Heiden E, Peek-Asa C. Hospitalisations for sport-related concussions in US children aged 5 to 18 years during 2000-2004. Br J Sports Med. 2008;42(8):664-669. 
16. Feudtner C, Christakis DA, Connell FA. Pediatric deaths attributable to complex chronic conditions: a population-based study of Washington State, 1980-1997. Pediatrics. 2000;106(1):205-209.

17. Peltz $A, W u C L$, White $M L$, et al. Characteristics of rural children admitted to pediatric hospitals. Pediatrics. 2016;137(5): e20153156.

18. Services UDoHaH. Annual update of the HHS Poverty Guidelines. Federal Register; 2016-03-14 2011.

19. Hart LG, Larson EH, Lishner DM. Rural definitions for health policy and research. Am J Public Health. 2005;95(7):1149-1155.

20. Proposed Matrix of E-code Groupings|WISQARS | Injury Center |CDC. 2016; http://www.cdc.gov/injury/wisqars/ecode_matrix.html.

21. Zemek RL, Farion KJ, Sampson M, McGahern C. Prognosticators of persistent symptoms following pediatric concussion: A systematic review. JAMA Pediatr. 2013;167(3):259-265.

22. Meehan WP, Mannix R. Pediatric concussions in United States emergency departments in the years 2002 to 2006. J Pediatr. 2010;157(6):889-893.

23. Davis GA, Purcell LK. The evaluation and management of acute concussion differs in young children. Br J Sports Med. 2014;48(2):98-101.

24. Zemek R, Barrowman N, Freedman SB, et al. Clinical risk score for persistent postconcussion symptoms among children with acute concussion in the ED. JAMA. 2016;315(10):1014-1025

25. Hinds PS, Hockenberry M, Rai SN, et al. Nocturnal awakenings, sleep environment interruptions, and fatigue in hospitalized children with cancer. Oncol Nurs Forum. 2007;34(2):393-402

26. Patterson ZR, Holahan MR. Understanding the neuroinflammatory response following concussion to develop treatment strategies. Front Cell Neurosci. 2012;6:58.

27. Meehan WP. Medical therapies for concussion. Clin Sports Med. 2011;30(1):115-124, ix

28. Petraglia AL, Maroon JC, Bailes JE. From the field of play to the field of combat: a review of the pharmacological management of concussion. Neurosurgery. 2012;70(6):1520-1533.

29. Giza CC, Kutcher JS, Ashwal S, et al. Summary of evidence-based guideline update: evaluation and management of concussion in sports: Report of the Guideline Development Subcommittee of the American Academy of Neurology. Neurology. 2013;80(24):2250-2257.

30. Barlow KM, Crawford S, Stevenson A, Sandhu SS, Belanger F, Dewey D. Epidemiology of postconcussion syndrome in pediatric mild traumatic brain injury. Pediatrics. 2010;126(2):e374-e381.

31. Keren R, Shah SS, Srivastava R, et al. Comparative effectiveness of intravenous vs oral antibiotics for postdischarge treatment of acute osteomyelitis in children. JAMA Pediatr. 2015;169(2):120-128

32. Hartling L, Bellemare S, Wiebe N, Russell K, Klassen TP, Craig W. Oral versus intravenous rehydration for treating dehydration due to gastroenteritis in children. Cochrane Database Syst Rev. 2006(3):CD004390.

33. Zonfrillo MR, Kim KH, Arbogast KB. Emergency Department Visits and Head Computed Tomography Utilization for Concussion Patients From 2006 to 2011. Acad Emerg Med. 2015;22(7):872-877.

34. Fieldston ES, Shah SS, Hall M, et al. Resource utilization for observation-status stays at children's hospitals. Pediatrics. 2013;131(6):1050-1058. 